\title{
A BRONCHOSCOPIC ADAPTOR FOR INTERMITTENT POSITIVE PRESSURE BREATHING IN CHILDREN
}

D. A. Pelton, M.D., F.R.C.P.(C), AND A. W. ConN, M.D., B.SC. (MED.), F.R.C.P.(c) ${ }^{\circ}$

DuRING BRoNchoscopy, inadequate ventilation may occur secondary to breathholding or respiratory depression. When necessary, the lungs can be inflated by occluding the bronchoscope and using a high flow of anaesthetic gases through the side arm. However, the light carrier may interfere with complete occlusion by a thumb or finger, resulting in an excessive leakage of gas and inadequate positive pressure. Recently, a modification was made to the C. L. Jackson bronchoscope by Dr. B. Fearon, ${ }^{1}$ which elevated the end of the bronchoscope and allowed better occlusion and ventilation. Nevertheless, this technique of intermittent application of positive pressure to the airway remains unsatisfactory as it (a) interferes with the endoscopist, $(b)$ prolongs the procedure, and $(c)$ fails to ensure adequate ventilation.

Four years ago, an adaptor to "cap" the end of the bronchoscope was introduced in the Department of Anaesthesia at the Hospital for Sick Children to overcome these difficulties (Fig. 1). It has since undergone many modifications

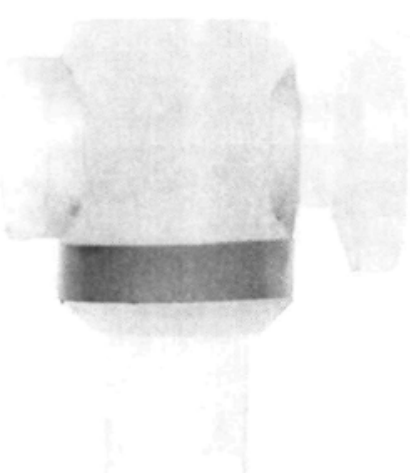

Frgure 1

and improvements in design. Currently, an Ayre's T-piece (MIE), including a length of corrugated tubing, and a reservoir bag, is attached to the adaptor (Fig. 2 ). This permits the entry of gases from the anaesthetic machine and allows either spontaneous or controlled ventilation.

The side arm of the adaptor, which accepts the T-piece, will move $360^{\circ}$ about the central position of the adaptor. The central portion has multiple ports in its wall to allow the free passage of gases through the side arm into the adaptor and lumen of the bronchoscope. The adaptor fits over the outside surface of the shoulder of the bronchoscope.

${ }^{\circ}$ Hospital for Sick Children, Toronto. 


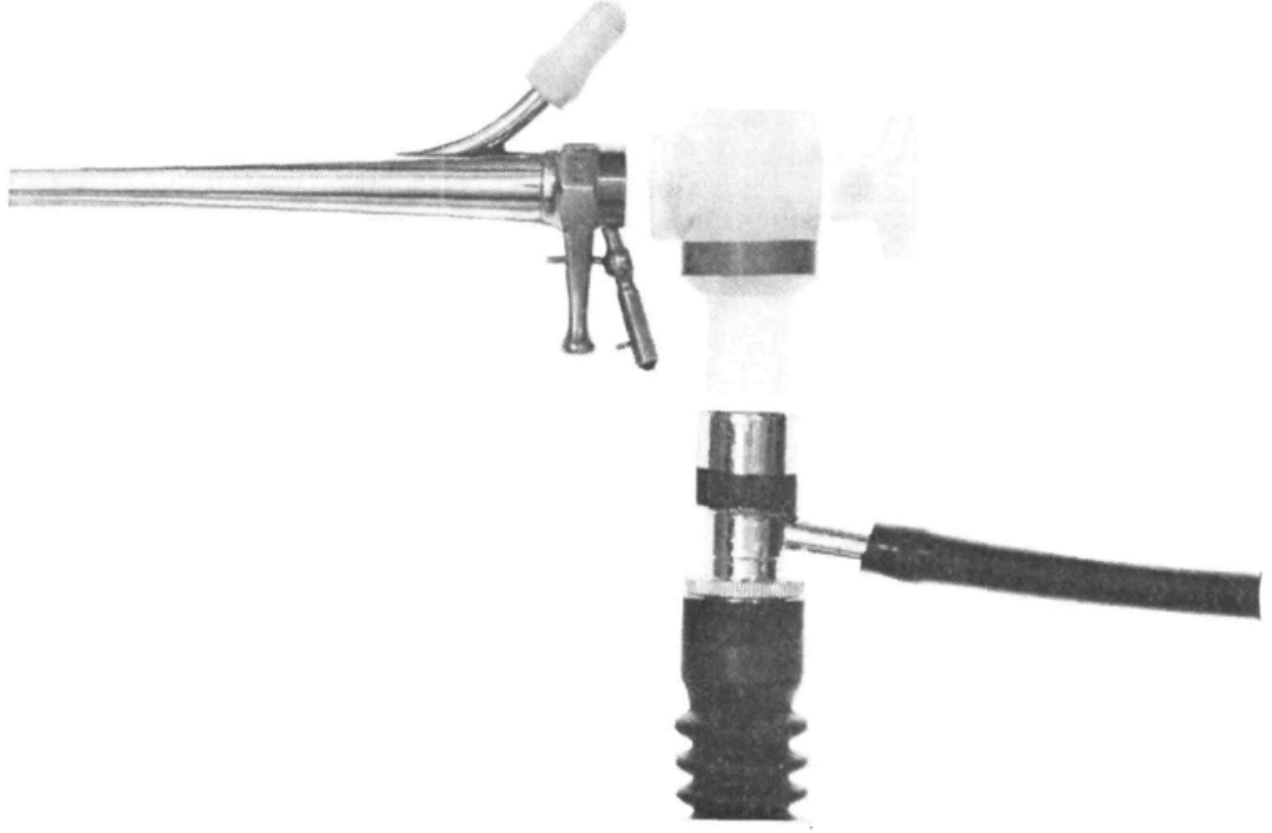

Figure 2

The proximal end has a "cap" with a window which allows visualization by the endoscopist. It is easily removed for performing aspiration of secretions, removing foreign bodies, and obtaining biopsy specimens or performing surgical procedures.

The adaptor is made of opaque, high-grade Polycarbinate. It is shatter-proof, has a hard surface, and will withstand all the common solutions used in cold sterilization of equipment. The material is resistant to temperatures between $-80^{\circ}$ and $400^{\circ} \mathrm{F}$. However, iodine solutions maybe discolour the material, and surface deterioration may occur with prolonged use of concentrated camphor. The window "glass" is made of clear polycarbinate and does not deteriorate.

\section{REFERENCE}

1. Fearon, et al. The Idiopathic Respiratory Distress Syndrome in the Newborn. Ann. Otol. Rhinol. \& Laryngol. 73: 1082 (1964). 